\section{P1-S2.57 USING AN ONLINE SURVEY TO INVESTIGATE RISK BEHAVIOURS AND SOCIAL NETWORKS IN A SYPHILIS OUTBREAK AMONG MEN WHO HAVE SEX WITH MEN IN TORONTO}

doi:10.1136/sextrans-2011-050108.114

${ }^{1} \mathrm{R}$ Shahin, ${ }^{2} \mathrm{C}$ Rank, ${ }^{2} \mathrm{~B}$ Kinniburgh, ${ }^{2} \mathrm{~A}$ Jolly, ${ }^{1} \mathrm{D}$ Al-Bargash, ${ }^{1} \mathrm{~B}$ Clarke, ${ }^{2} \mathrm{M}$ Ofner, ${ }^{2} \mathrm{M}$ L Gilbert. ${ }^{1}$ Toronto Public Health, Toronto Canada; ${ }^{2}$ Public Health Agency of Canada, Ottawa, Canada

Background An outbreak of infectious syphilis among men who have sex with men (MSM) in Toronto began in 2002 and peaked in 2009 when 579 cases were reported. We developed an internet-based enhanced surveillance tool to investigate HIV coinfection, sexual risk behaviours, and social networks among a sample of cases in 2010.

Methods Males with infectious syphilis in Toronto from 15 April 2010 to 30 June 2010 were invited to complete a self-administered online survey. Data were collected on sexual partners, risk behaviours, condom use, and venues where respondents looked for sex partners in the 6 months before syphilis infection. We assessed key survey variables by HIV status, and carried out social network analyses to examine links between cases, sexual contacts and venues.

Results Of 84 eligible cases, 46 were successfully contacted and 27 completed the survey. Three of 27 respondents (11\%) identified sexual contacts and $16(59 \%)$ reported having multiple sex partners during routine case follow-up. In the online survey, almost all men $(n=26)$ reported at least one male sex partner in the six months before syphilis infection (median 5 partners; IOR 2-12). HIV prevalence among respondents was $70 \%$ (vs 35\% among nonrespondents, $\mathrm{p}<0.01)$. Predominant risk behaviours were anonymous sex (64\%), group sex (56\%), and 55\% indicated participation in barebacking ( $63 \%$ of HIV-positive and $33 \%$ of HIV-negative men). Of 19 HIV-positive respondents, 17 (89\%) had at least one HIVpositive partner; condom use with HIV-positive partners was low (16\% and $28 \%$ used condoms all or most times during receptive and insertive anal sex, respectively). Among 25 cases who provided information on venues where they looked for sex partners, most sought partners online (88\%), at bathhouses $(60 \%)$ or bars $(36 \%) ; 22$ cases were linked by six common venues-three websites, two bathhouses and one bar.

Conclusions A substantial proportion of men in our sample reported multiple sex partners and low condom use. As respondents were predominantly HIV-positive MSM with seroconcordant sex partners, risk behaviours, venue attendance and patterns of condom use may not be representative of all MSM with syphilis in Toronto. Nevertheless, collection of behavioural data using an online survey allowed for enhanced descriptive analyses beyond the scope of routine surveillance. In addition to social network analyses, these data are useful to inform targeted prevention and control efforts.

\section{P1-S2.58 THE ROLE OF VENUES IN STRUCTURING STI AND RISK NETWORKS AMONG MEN WHO HAVE SEX WITH MEN}

doi:10.1136/sextrans-2011-050108.115

${ }^{1} \mathrm{~L}$ Drumright, ${ }^{2} \mathrm{~S}$ Weir, ${ }^{3} \mathrm{~S}$ Frost. ${ }^{1}$ Imperial College London, London, UK; ${ }^{2}$ UNC, Chapel Hill, USA; ${ }^{3}$ University of Cambridge, Cambridge, UK

Background Venues (eg, bars, the Internet) are believed to structure STI risk networks, however it is difficult to separate "risky places" from "risky people", as venues are comprised of the people who attend them. To determine how venues may structure HIV/STI risk, we analysed data collected within social meeting places with "causal inference" statistical approaches, which aim to mimic randomising individuals to venues.
Methods Between 11/2007 and 3/2009, we visited 14 venues in San Diego, California, previously identified as places where men meet male sexual partners. 660 male patrons were interviewed anonymously by computer assisted self interview; 609 reported having ever had sex with a man. We analysed associations between the interview venue and participants' demographics, self-reported HIV and STI status, risk behaviours, and drug use. We used a marginal structural model to test associations between HIV/STI and venue, weighting by age, ethnicity, education, number of sexual partners in the past year, and number of HIV+ individuals known, in order to control for collinearity between venue and these patron characteristics.

Results The mean age of MSM was 34 yrs; $55 \%$ reported white, $24 \%$ Hispanic, and 8\% African American ethnicity; 89\% reported at least some college education. $35 \%$ reported history of STI and $13 \%$ reported that they were HIV-infected. The median number of lifetime male partners reported was 30, with 15\% reporting unprotected receptive anal sex with at least five partners in the past 12 months. 39\% reported ever meeting a sexual partner at the venue of interview. In univariate analyses, the 14 venues differed significantly by participants' reported age, ethnicity, number of lifetime male partners, past STI infection, HIV + status, number of HIV+ individuals known, and finding partners at that venue. In multivariable analyses using marginal structural models, after controlling for participants characteristics, venues demonstrated significant structuring of HIV+ status, past STI, and methamphetamine (see Abstract P1-S2.58 figure 1)

\section{Abstract P1-S2.58 Figure 1}

Conclusions We demonstrated significant population structure in demographics, social networks, and HIV and STI status among MSM, which may assist in targeted surveillance and prevention. Interview venue may be associated with HIV, STIs and risk behaviours, separate from commonly collected individual-level data. In order to ensure successful in'terventions, a more thorough mechanistic understanding of how risky venues "emerge is needed."

\section{P1-S2.59 OROPHARYNGEAL HUMAN PAPILLOMAVIRUS (HPV) PREVALENCE AND RISK FACTORS IN MEN HAVING SEX WITH MEN (MSM)}

doi:10.1136/sextrans-2011-050108.116

${ }^{1} \mathrm{~T}$ Read, ${ }^{1} \mathrm{~L}$ Vodstrcil, ${ }^{2} \mathrm{~S}$ Tabrizi, ${ }^{2} \mathrm{~S}$ Garland, ${ }^{3} \mathrm{~A}$ Grulich, ${ }^{1} \mathrm{~J}$ Hocking, ${ }^{4} \mathrm{~B}$ Catriona, ${ }^{4} \mathrm{M}$ Chen, ${ }^{1} \mathrm{M}$ McCullough, ${ }^{1} \mathrm{C}$ Fairley. ${ }^{1}$ University of Melbourne, Carlton, Australia, ${ }^{2}$ Royal Women's Hospital, Melbourne, Australia; ${ }^{3}$ University of New South Wales, Australia; ${ }^{4}$ Alfred Hospital, Australia

Background HPV-associated oropharyngeal cancers are becoming more common. We sought to determine the prevalence of, and risk factors for oropharyngeal HPV infection in MSM, and to compare the sensitivity of throat swab, oral rinse and absorbed rinse specimens.

Methods Cross-sectional study of 500 MSM (half with HIV infection) attending Melbourne Sexual Health Centre in 2010. Men completed a behavioural questionnaire, provided a selfadministered throat swab and a gargled saline sample. Half the saline was absorbed in a tampon, to be suitable for postage. If HPV was present on type-common polymerase chain reaction, it was typed by linear array. ORs for risk factors were calculated by logistic regression.

Results At least one type of HPV was found in 74 of 500 men, a prevalence of $14.8 \%$ (95\% CI $11.7 \%$ to $17.9 \%$ ) and HPV type 16 was 